\title{
A novel potential effective strategy for enhancing the antitumor immune response in breast cancer patients using a viable cancer cell-dendritic cell-based vaccine
}

\author{
MONA S. ABDELLATEIF ${ }^{1}$, SABRY M. SHAARAWY ${ }^{1}$, EMAN Z. KANDEEL ${ }^{2}$, \\ AHMED H. EL-HABASHY ${ }^{3}$, MOHAMED L. SALEM ${ }^{4}$ and MOTAWA E. EL-HOUSEINI ${ }^{1}$ \\ ${ }^{1}$ Medical Biochemistry and Molecular Biology Unit, Department of Cancer Biology; Departments \\ of ${ }^{2}$ Clinical Pathology and ${ }^{3}$ Pathology, National Cancer Institute, Cairo University, Cairo 11976; \\ ${ }^{4}$ Department of Zoology, Faculty of Science, Tanta University, Tanta, Gharbia 31511, Egypt
}

Received March 17, 2017; Accepted November 16, 2017

DOI: $10.3892 /$ ol.2018.8631

\begin{abstract}
Dendritic cells (DCs) have been used in a number of clinical trials for cancer immunotherapy; however, they have achieved limited success in solid tumors. Consequently the aim of the present study was to identify a novel potential immunotherapeutic target for breast cancer patients through in vitro optimization of a viable DC-based vaccine. Immature DCs were primed by viable MCF-7 breast cancer cells and the activity and maturation of DCs were assessed through measuring CD83, CD86 and major histocompatibility complex (MHC)-II expression, in addition to different T cell subpopulations, namely $\mathrm{CD}^{+} \mathrm{T}$ cells, $\mathrm{CD} 8^{+} \mathrm{T}$ cells, and $\mathrm{CD} 4^{+} \mathrm{CD} 25^{+}$

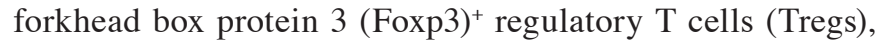
by flow cytometric analysis. Foxp3 level was also measured by enzyme-linked immunosorbent assay (ELISA) in addition to reverse-transcription quantitative polymerase chain reaction. The levels of interleukin-12 (IL-12) and interferon- $\gamma$ $(\mathrm{IFN}-\gamma)$ were determined by ELISA. Finally, the cytotoxicity of cytotoxic T lymphocytes (CTLs) was evaluated through measuring lactate dehydrogenase (LDH) release by ELISA. The results demonstrated that $\mathrm{CD}^{+} 3^{+}, \mathrm{CD} 86^{+}$and $\mathrm{MHC}-\mathrm{II}^{+}$ DCs were significantly elevated $(\mathrm{P}<0.001)$ following priming with breast cancer cells. In addition, there was increased activation of $\mathrm{CD}^{+}$and $\mathrm{CD} 8^{+} \mathrm{T}$-cells, with a significant decrease of $\mathrm{CD} 4^{+} \mathrm{CD} 25^{+} \mathrm{Foxp}^{+}$Tregs $(\mathrm{P}<0.001)$. Furthermore, a significant downregulation of FOXP3 gene expression $(\mathrm{P}<0.001)$ was identified, and a significant decrease in the level of its protein
\end{abstract}

Correspondence to: Dr Mona S. Abdellateif, Medical Biochemistry and Molecular Biology Unit, Department of Cancer Biology, National Cancer Institute, Cairo University, 1 Fom Elkhalig Square, El Kasr El Ainy, Cairo 11976, Egypt

E-mail: mona.sayed@cu.edu.eg

Key words: breast cancer, dendritic cells, Foxp3, lactate dehydrogenase, cytotoxic T-lymphocyte, interleukin 12, interferon- $\gamma$, MCF-7 breast cancer cells following activation $(\mathrm{P}<0.001)$ was demonstrated by ELISA. Additionally, significant increases in the secretion of IL-12 and IFN- $\gamma(\mathrm{P}=0.001)$ were observed. LDH release was significantly increased $(\mathrm{P}<0.001)$, indicating a marked cytotoxicity of CTLs against cancer cells. Therefore viable breast cancer cell-DC-based vaccines could expose an innovative avenue for a novel breast cancer immunotherapy.

\section{Introduction}

Breast cancer is the second-leading cause of cancer-associated mortality among women worldwide (1) and constitutes $22.9 \%$ of cancer cases in women (2). In Egypt, it was reported that breast cancer represented $\sim 38.2 \%$ of female malignancies (3). Despite advancements in treatment strategies, metastatic breast cancer remains incurable, with available therapies predominantly aiming to provide symptomatic relief and extend the overall survival time of the patient (4).

The development of effective vaccines for specific tumor cell antigens is uncomplicated; however, this approach has achieved limited success in solid tumors, particularly in the case of breast cancer (5). This is due to the number of breast cancer cell subgroups, which vary in morphology, biology, behavior and response to therapy (5). Constructing an effective, reliable, tolerable and safe cancer vaccine is the core principle of cancer immunotherapy. Dendritic cells (DCs) are critical players in producing an antitumor immune response and have been employed as a cellular cancer vaccine in a number of clinical trials $(6,7)$. Using DCs provides a unique immune response against tumor-associated antigens (TAAgs); therefore, DC-based vaccines are capable of regulating and maintaining $\mathrm{T}$ cell functions that generate an effective cellular immune response $(8,9)$.

The present study was designed to construct a potential breast cancer vaccine in which DCs were primed by intact viable cancer cells. This strategy is advantageous in that the cancer cells provide a full complement of TAAgs, including major histocompatibility complex (MHC) class I and class II-restricted epitopes, and can provoke an immune response against numerous unknown tumor antigens and may therefore 
overcome the hazards of immunological escape by antigen loss variants.

\section{Materials and methods}

Patient selection. The current study was conducted using 30 patients with breast cancer lesions and 15 age-matched healthy controls. The patients presented to the Surgical Oncology Unit of the National Cancer Institute (NCI), Cairo University (Cairo, Egypt), between March 2014 and June 2016. The ethics committee of the NCI of Egypt approved the study, and written informed consent was obtained from patients prior to enrollment.

MCF-7 breast cancer cell line. MCF-7 cells were obtained frozen in liquid nitrogen $\left(-180^{\circ} \mathrm{C}\right)$ from the American Type Culture Collection (Manassas, VA, USA). The tumor cell line was maintained via serial sub-culturing in RPMI-1640 medium supplemented with $10 \%$ heat-inactivated fetal bovine serum (FBS), $100 \mathrm{U} / \mathrm{ml}$ penicillin and $100 \mu \mathrm{g} / \mathrm{ml}$ streptomycin (Biowest LLC, Kansas City, MO, USA) in a humidified incubator at $37^{\circ} \mathrm{C}$ with $5 \% \mathrm{CO}_{2}$, at the Cancer Biology Lab of the NCI.

Isolation of mononuclear cells and production of DCs and lymphocytes. Mononuclear cells were isolated from peripheral blood by Ficoll-Hypaque density gradient centrifugation (Biowest LLC, Riverside, MO, USA). Centrifuging was performed at $60-100 \mathrm{x}$ g for $30-40 \mathrm{~min}$ at $18-20^{\circ} \mathrm{C}(10,11)$. The mononuclear cells were cultured in RPMI-1640 medium supplemented with $10 \%$ heat-inactivated FBS, $100 \mathrm{U} / \mathrm{ml}$ penicillin and $100 \mu \mathrm{g} / \mathrm{ml}$ streptomycin for $24 \mathrm{~h}$ in a humidified incubator at $37^{\circ} \mathrm{C}$ with $5 \% \mathrm{CO}_{2}$. The non-adherent cells (lymphocytes) were removed by gently washing with pre-warmed $\left(37^{\circ} \mathrm{C}\right)$ tissue culture medium containing recombinant human interleukin (IL)-2 (2 ng/ml). The adherent cells (monocytes) were cultured in RPMI-1640 medium containing recombinant human cytokines, granulocyte monocyte-colony stimulating factor (GM-CSF) and IL-4 (700 and $500 \mathrm{IU} / \mathrm{ml}$, respectively; Koma Biotech Inc., Seoul, South Korea), thereby producing immature DCs.

Immature DC (IDC) loading with MCF-7 breast cancer cells. On day 5 of culture, IDCs were co-cultured with MCF-7 breast cancer cells for $24 \mathrm{~h}$ at a ratio of 10:1 in RPMI-1640 medium with $10 \% \mathrm{FBS}, 100 \mathrm{U} / \mathrm{ml}$ penicillin and $100 \mu \mathrm{g} / \mathrm{ml}$ streptomycin in a humidified incubator at $37^{\circ} \mathrm{C}$ with $5 \% \mathrm{CO}_{2}$ to generate mature DCs (MDCs).

T cell priming by autologous MDCs. Lymphocytes were counted and added to the flask of co cultured MDCs and MCF-7 cell line at ratio of (lymphocytes: DCs; 10:1) for 2 days. The count was estimated upon characterization of DCs using a flow cytometer and confirmed using a hemocytometer. Note that mature DCs are not adherent to the flask compared with the tumor cell line. A number of time periods were investigated (not shown) and the time period of least duration with favorable results [increased expression of cluster of differentiation $(\mathrm{CD}) 4^{+}, \mathrm{CD}^{+}$and decreased expression of $\mathrm{CD} 4{ }^{+} \mathrm{CD} 25^{\text {bright }} \mathrm{Foxp}^{+}$] was selected, as the present study aimed to make a simple immunotherapeutic model in the shortest time possible.

Cytokine detection via ELISA. Media was obtained prior to and following co-culture of DCs and T cells for estimation of interferon- $\gamma($ IFN- $\gamma$ ), IL-12 (cat nos. K0331121 and K0331124, respectively; Koma Biotech Inc.) and Foxp3 (cat no. 201702; Glory Science Co., Ltd, Shanghai, China) via an ELISA, according to the manufacturer's protocol. Cytokine release was reported as the mean \pm standard error of the mean (SEM).

Flow cytometric analysis. DC phenotypes were determined using monoclonal anti-human CD86-FITC, CD83-PE and MHC-II-APC antibodies (cat nos. FAB141F, FAB1774P and IC7169A, respectively; R\&D System, Inc., Minneapolis, $\mathrm{MN}$, USA) prior to and following loading with tumor cells. T-cell immunophenotype characterization was conducted via CD3-APC, CD4-FITC, CD8-PE conjugate (cat no. 15080668, eBioscience, Inc.), CD25-ECD and Foxp3 PE-CY7 (cat nos. 4238109 and 560046, respectively; Beckman Coulter, Inc., USA). For surface markers, samples were stained according to the manufacturer's protocol. Cells were lysed and washed twice with PBS, centrifuged at $1800 \mathrm{rpm}$ for $3 \mathrm{~min}$ and incubated for $30 \mathrm{~min}$ in darkness at room temperature. Foxp3 was prepared using an IntaPrep permeabilization kit (Beckman Coulter, Inc., Brea, CA, USA). Intracellular staining was performed using IntaPrep permeabilization reagent, by which cells were fixed with reagent 1 (fixation reagent using formaldehyde). Following washing, cells were permeabilized using reagent 2 (using Saponine for permeability). Buffer was supplied from a Foxp3/Transcription Factor Staining Buffer Set (00-5523; eBioscience; Thermo Fisher Scientific. Inc., Waltham, MA, USA). Samples were analyzed using a flow cytometer (NAVIOS; Beckman Coulter, Inc., Figs. 1 and 2).

Detection of cytotoxicity produced by activated CTLs. Cytotoxicity was assessed by measuring LDH release from the MCF-7 breast cancer cell line prior to and following co culture with CTL for 2 days, using an ELISA (cat no. SEB864Hu, Cloud-Clone Corp., Katy, TX, USA) according to the manufacturer's protocol. T cells were added to the population of tumor cells and DCs in the same flask to ensure that antigen presentation, $\mathrm{T}$ cell activation and exposure to tumor cells occurred simultaneously in order to mimic what occurs in the tumor microenvironment, and allow interactions with different cytokines. This was a preliminary step for immunotherapy preparation.

Reverse transcription-quantitative polymerase chain reaction (RT-qPCR) assay of FOXP3 gene expression in CTLs. RNA was purified from samples using the SV Total RNA Isolation System (Promega Corporation, Madison, WI, USA), and cDNA was produced using a High-Capacity cDNA Reverse Transcription kit (Applied Biosystems; Thermo Fisher Scientific, Inc.), conducted according to the manufacturer's protocols. Two primer sets were designed to eliminate the possibility of primer dimer formation and nonspecific annealing using Primer3 (version 4.0; http://bioinfo.ut.ee/primer3-0.4.0/) and oligoanalyzer 3.1 (https://eu.idtdna.com/calc/analyzer) software: One for the gene of interest, FOXP3 (forward, 5'-ACT 

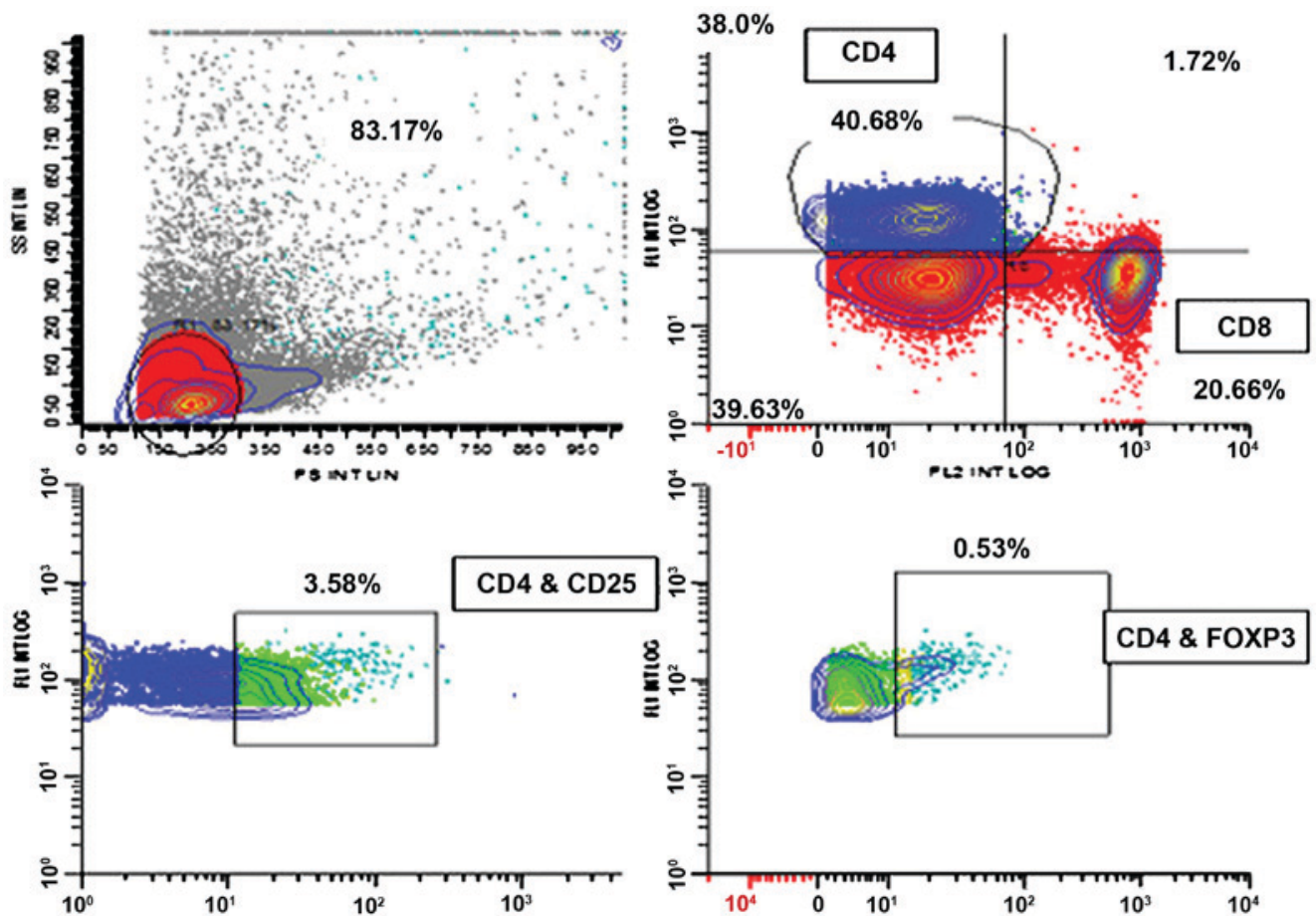

Figure 1. FOXP3 expression in normal control. The gating strategy based on gating on lymphoid region then $\mathrm{CD} 4^{+}$population then $\mathrm{CD} 44^{+} \mathrm{CD} 25^{+}$population and finally detecting the $\mathrm{CD} 4^{+} \mathrm{FOXP}^{+}$population. $\mathrm{FOXP} 3^{+}$, forkhead box protein 3 .

A
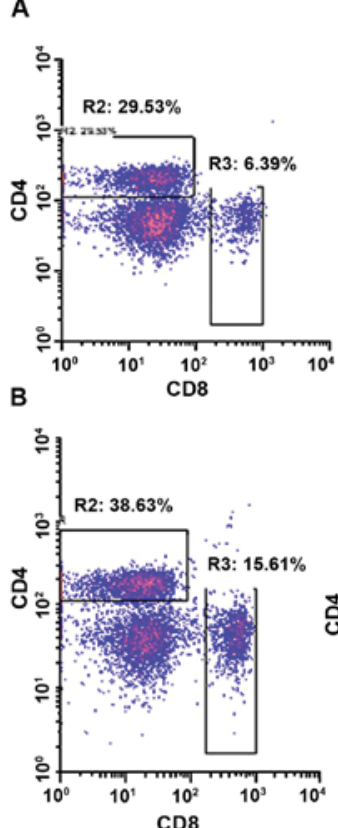
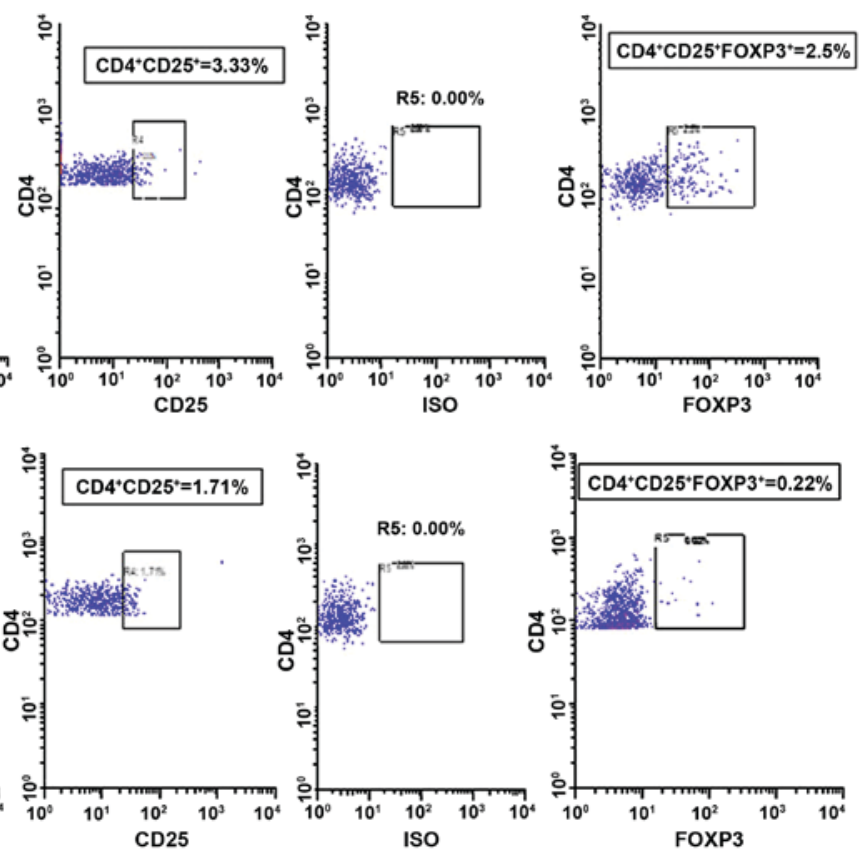

Figure 2. Measurement of $\mathrm{CD} 4^{+} \mathrm{CD} 8^{+}, \mathrm{CD} 4^{+} \mathrm{CD} 25^{+}$, and $\mathrm{CD} 4^{+} \mathrm{CD} 25^{+} \mathrm{FOXP} 3^{+}$before and after activation in breast cancer cases. (A) $\mathrm{CD} 4$ expression and $\mathrm{CD} 8$ in the first histogram. Second histogram $\mathrm{CD} 4^{+} \mathrm{CD} 25^{+}$gated on $\mathrm{CD} 4^{+}$population. Third histogram is $\mathrm{CD} 4^{+}$against isotype control. The last histogram is estimating $\mathrm{CD}^{+} \mathrm{FOXP}^{+}$gated on $\mathrm{CD} 4^{+} \mathrm{CD} 25^{+}$, before activation with D.C based vaccine. (B) $\mathrm{CD} 4^{+}$and $\mathrm{CD} 8^{+}$expression were increased. $\mathrm{CD} 4{ }^{+} \mathrm{CD} 25^{+}$as well as $\mathrm{CD} 4^{+} \mathrm{CD} 25^{+} \mathrm{FOXP} 3^{+}$were much reduced after activation with D.C based vaccine. FOXP3+, forkhead box protein 3.

GACCAAGGCTTCATCTGTG-3'; and reverse, 5'-GGAACT CTGGGAATGTGCTGT-3'); and one for the housekeeping gene $\beta$-actin (forward, 5'-ATGATATCGCCGCGCTCA-3'; and reverse, 5'-CGCTCGGTGAGGATCTTCA-3'). Expression levels of $\beta$-actin were measured as a reference for the target gene expression. Each PCR was performed in a final volume of $10 \mu \mathrm{l}$, including $1 \mu \mathrm{g}$ of the cDNA product, $1 \mu \mathrm{l}(50 \mathrm{nM})$ of each primer and $2 \mathrm{X}$ reaction mixtures containing Fast Start DNA polymerase, reaction buffer, dNTPs, and SYBR-Green (Applied Biosystems; Thermo Fisher Scientific, Inc.) according to the manufacturer's protocol (12). The thermal cycling conditions comprised a temperature profile of $95^{\circ} \mathrm{C}$ for $10 \mathrm{~min}$ for denaturation, followed by 40 cycles $\left(95^{\circ} \mathrm{C}\right.$ for $15 \mathrm{sec}$ and $60^{\circ} \mathrm{C}$ for $60 \mathrm{~min}$ ) in a ViiA ${ }^{\mathrm{TM}} 7$ Real-Time PCR System (Applied 
Biosystems; Thermo Fisher Scientific, Inc.). The RT-qPCR amplification products were analyzed via melting curve analysis.

The relative expression of gene transcripts was calculated according to the $\Delta \mathrm{Cq}$ and $2^{-\Delta \Delta \mathrm{Cq}}$ formulas according to Schmittgen and Livak (13). Finally, the ratios of target to reference gene were determined with the Pfaffl method (14).

Statistical analysis. Statistical analysis was conducted using SPSS version 24 (IBM Corp., Armonk, NY, USA). Data are expressed as the mean \pm SEM. Comparison between groups was performed using paired Student's t-test for comparison between variables prior to and following activation. Pearson correlation analysis was applied for quantitative variables. $\mathrm{P}<0.05$ was considered to indicate a statistically significant difference.

\section{Results}

DC activation and maturation ex vivo by exposure to tumor antigens of viable breast cancer cells. The present study was conducted on 30 patients with breast cancer and 15 control healthy females with mean ages of $53.9 \pm 10.9$ and $50 \pm 9.4$ years, respectively (Table I). CD83 and CD86 were significantly increased on DCs isolated from breast cancer patients and healthy controls $(\mathrm{P}<0.001)$ following loading with viable MCF breast cancer cells for $24 \mathrm{~h}$ (Fig. 3).

Activation of CTLs. The activation of T lymphocytes was confirmed by the upregulation of $\mathrm{CD} 4, \mathrm{CD} 8$ and $\mathrm{CD} 3$, detected by flow cytometric analysis. Significant increases in the levels of $\mathrm{CD} 4^{+} \mathrm{T}$-helper (Th) cells and $\mathrm{CD} 8^{+} \mathrm{CTLs}$ were observed $(\mathrm{P}<0.001$; Fig. $4 \mathrm{~A}$ and $\mathrm{B})$. However, there was a significant decrease in the $\mathrm{CD} 4{ }^{+} \mathrm{CD} 25^{\text {+bright }} \mathrm{Foxp} 3^{+}$ regulatory $\mathrm{T}$ cell $($ Treg) subpopulation $(\mathrm{P}<0.001)$ isolated from breast cancer patients and healthy controls following activation with MDCs previously loaded with whole viable MCF-7 cells (Fig. 4C and D).

Cytokine detection by ELISA. The effect of priming DCs with viableMCF-7 breast cancercells resulted in a significantincrease in IL-12 secretion in the media of DCs from breast cancer patients and healthy controls $(\mathrm{P}<0.001)$. Furthermore, activation of Th cells by the vaccine resulted in a significant elevation in the IFN- $\gamma$ level in the media of T cells isolated from breast cancer patients and healthy controls $(\mathrm{P}=0.001$; Fig. $5 \mathrm{~A}$ and $\mathrm{B})$. This was confirmed by the significant association between the IL-12 and IFN- $\gamma$ levels $(\mathrm{P}<0.05 ; \mathrm{r}=0.399)$. IL-12 also positively correlated with $\mathrm{LDH}(\mathrm{P}<0.05 ; \mathrm{r}=0.418)$. There was a significant decrease in Foxp3 released in the media of $\mathrm{T}$ cells isolated from breast cancer patients and healthy controls $(\mathrm{P}<0.001)$ following activation with MDCs previously loaded with whole viable cancer cells (Fig. 5C).

Detection of CTL cytotoxicity. There was a significant elevation in LDH release in the media of MCF-7 cells following mixing with CTLs induced by the whole viable cancer cell-primed DCs $(\mathrm{P}<0.001$; Fig. 5D).

RT-qPCR for Foxp3 gene expression. There was a significant decrease in FOXP3 gene expression in CTLs induced by the
Table I. Clinicopathological characteristics of 30 patients with breast cancer.

\begin{tabular}{lr}
\hline Characteristic & Number \\
\hline Diagnosis & \\
Invasive ductal carcinoma & 23 \\
Invasive lobular carcinoma & 4 \\
Tubular carcinoma & 2 \\
Papillary carcinoma & 1 \\
Grade & \\
I & 3 \\
II & 20 \\
III & 3 \\
IV & 4 \\
Axillary lymphadenopathy & \\
Yes & 23 \\
No & 7 \\
Distant metastasis & \\
Yes & 4 \\
No & 26 \\
Stage & \\
I & 6 \\
II & 4 \\
III & 16 \\
IV & 4 \\
\hline
\end{tabular}

DC-based vaccine $(\mathrm{P}<0.001)$. The fold change was $8.26 \pm 0.77$ prior to activation, and $0.92 \pm 0.09$ following activation (Fig. 6). In breast cancer patients, there was a significant inverse correlation between Foxp3 gene expression and the level of $\mathrm{CD} 4^{+}$ Th cells $(\mathrm{P}<0.05 ; \mathrm{r}=-0.389)$.

\section{Discussion}

A number of studies have been conducted to enhance the antitumor immune response in breast cancer through priming DCs; however, selecting and optimizing the antigen-loading strategy has been demonstrated to be a challenging undertaking $(6,8,15)$. The most common method is by using freeze-thawed ordinary lysates that are obtained by subjecting cancer cells to several freeze and thaw cycles using liquid nitrogen and water baths $(16,17)$. However, DCs loaded with such lysates have not provided complete protection against tumor responses in differential animal models $(16,18,19)$. Furthermore, in clinical trials, numerous studies have demonstrated that freeze-thawed lysates are ineffective for therapy as they suppress DC maturation and function $(17,20,21)$.

The present study attempted to optimize tumor antigen loading with DCs by a novel strategy. This was obtained by subjecting DCs isolated from breast cancer patients, or healthy controls as a comparison, to intact viable MCF-7 cells in complete conditioned RPMI-1640 medium. The activation of DCs was demonstrated by significantly increased levels of the stimulatory molecule CD86, maturation molecule CD83 and MHC-II. The elevation of such molecules may enhance the 
A

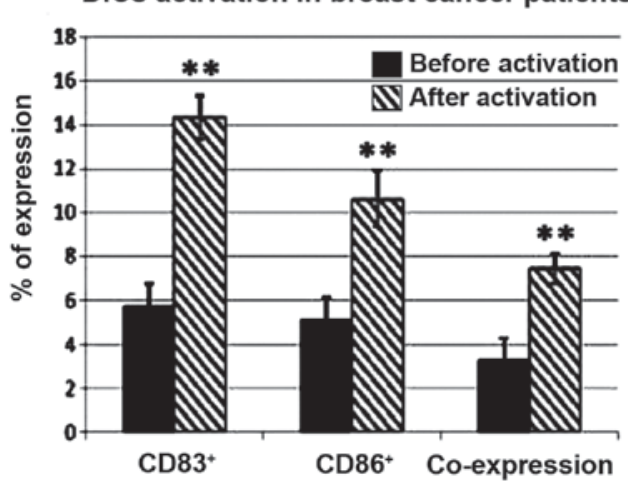

B D.Cs activation in control group

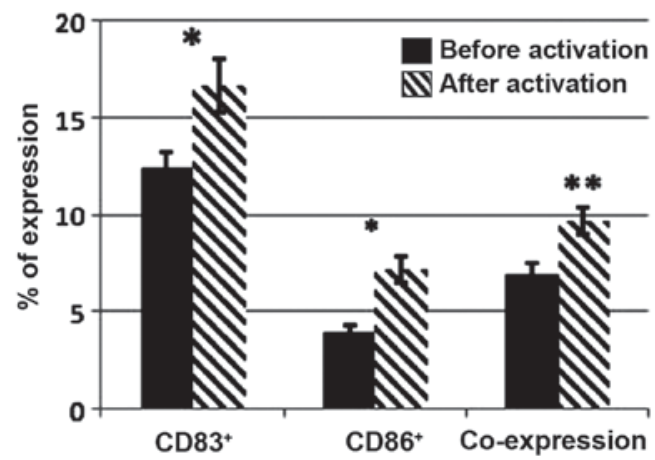

Figure 3. Expression of CD83 and CD86, and their co-expression in DCs from (A) breast cancer patients and (B) healthy controls following priming of DCs with MCF-7 breast cancer cells ex vivo. Data are presented as the mean \pm standard error of the mean. Statistical comparisons were performed using Student's t-tests. ${ }^{*} \mathrm{P}<0.05$ and ${ }^{* *} \mathrm{P}<0.001$ vs. before activation. $\mathrm{DC}$, dendritic cell.
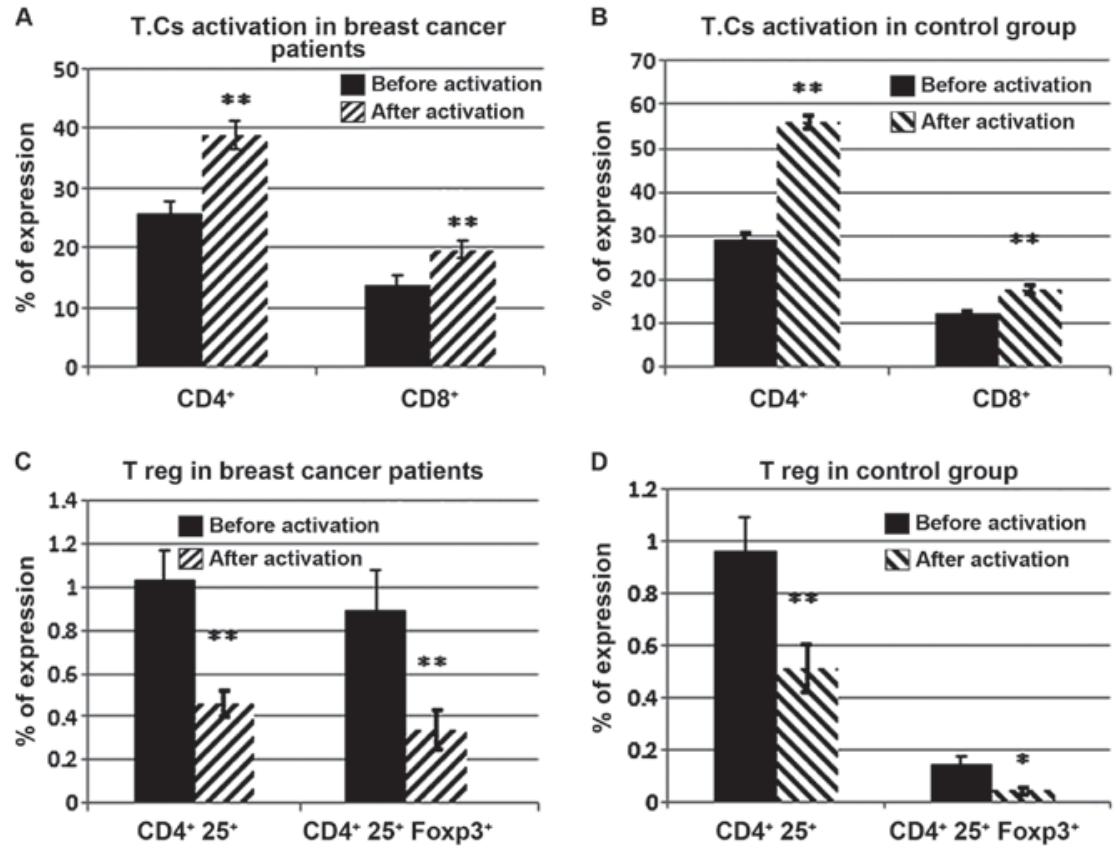

Figure 4. Expression levels of T-cell markers following activation with mature dendritic cells. CD4 and CD8 expression on T cells isolated from (A) breast cancer patients and (B) healthy controls. $\mathrm{CD} 4{ }^{+} \mathrm{CD} 25^{+}$and $\mathrm{CD} 4{ }^{+} \mathrm{CD} 25^{+} \mathrm{Foxp} 3^{+}$expression on Tregs isolated from (C) breast cancer patients and (D) healthy controls Data are presented as the mean \pm standard error of the mean. Statistical comparisons were performed using Student's t-tests. "P<0.05 and ${ }^{* * *} \mathrm{P}<0.001$ vs. before activation. Tregs, regulatory $\mathrm{T}$ cells.

capacity of DCs to prime T cell responses. By contrast, other studies have used DCs loaded with cell culture supernatants that may not have contained sufficient or adequate antigens secreted in the media (22). Additionally, a previous study demonstrated reduced levels of CD80, CD86 and CD40 in DCs loaded with irradiated tumor cells (23).

Another important feature of mature active DCs is the production of IL-12. In the present study, there was a significant increase in its secretion, from $160.03 \pm 10.27 \mathrm{pg} / \mathrm{ml}$ prior to activation to $254.60 \pm 12.67 \mathrm{pg} / \mathrm{ml}$ following activation of DCs with viable tumor antigens. IL-12 has a crucial importance in the differentiation of naive $\mathrm{T}$ cells into Th cells and subsequently in initiating an active specific immune response through the induction of IFN- $\gamma$ and tumor necrosis factor- $\alpha$ from $\mathrm{T}$ cells and natural killer cells, as demonstrated by Vieira et al (24).
The results of the present study revealed that the interaction of viable cancer cells and DCs resulted in stimulation of $\mathrm{CD} 4^{+} \mathrm{Th}$ cells and $\mathrm{CD} 8^{+} \mathrm{CTLs}$ against a wide range of tumor antigens. This was confirmed by the increased expression of $\mathrm{CD}^{+}, \mathrm{CD}^{+}$and $\mathrm{CD}^{+}$cells by flow cytometry, as well the increased secretion of IFN- $\gamma$ by reactive tumor antigen-specific $\mathrm{CD} 4^{+}$Th cells. An explanation for these findings is that these cells were capable of inducing IFN- $\gamma$ and TNF- $\alpha$, and serve a role in priming tumor-specific CTLs through the release of IL-2 (25). These results suggested that DC priming by whole, intact tumor cells induced a differential MHC class I and II cross-presentation of tumor antigen to $\mathrm{T}$ cells, as reported by Kini Bailur et al (26), and therefore induced a potent antitumor immune response.

Furthermore, this vaccine type resulted in a significant decrease in an important subset of $\mathrm{T}$ cells, $\mathrm{CD} 4{ }^{+} \mathrm{CD} 25^{+} \mathrm{Foxp} 3^{+}$ 

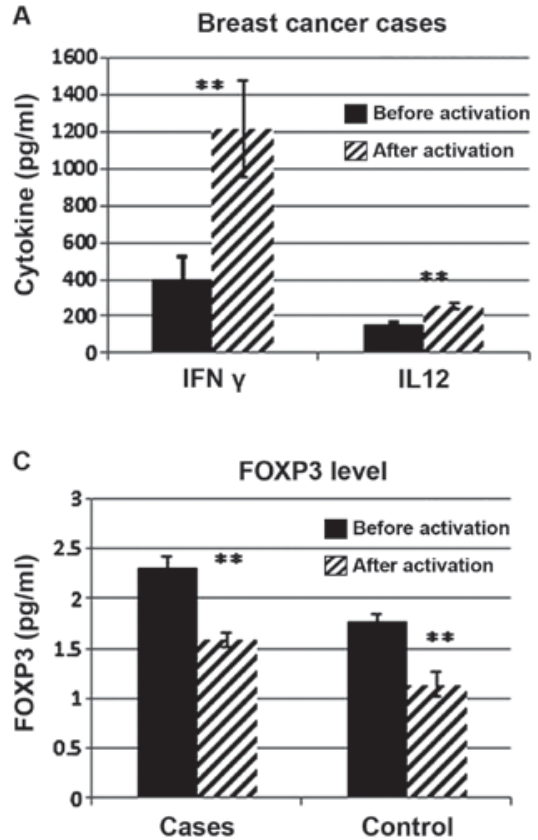

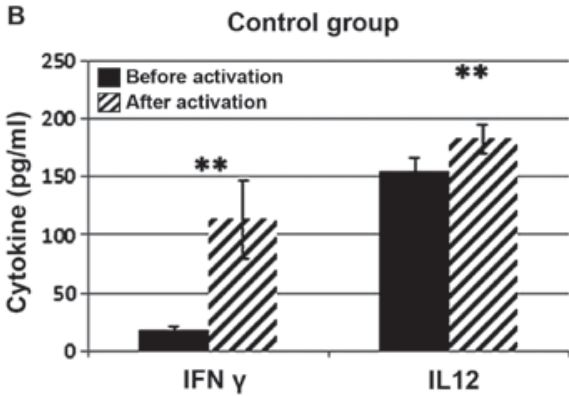

D

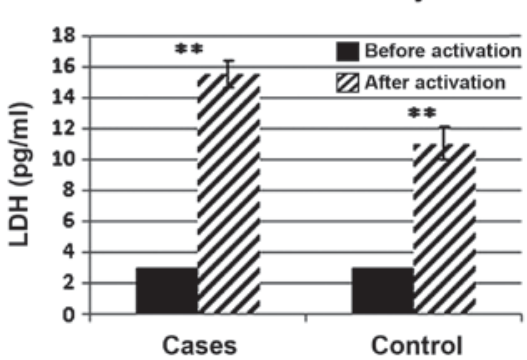

Figure 5. IFN- $\gamma$ and IL-12 levels prior to and following activation with DCs isolated from (A) breast cancer patients and (B) healthy controls. (C) Level of Foxp3 released into the media prior to and following activation with DCs in breast cancer patients and healthy controls. (D) LDH released in the media of MCF-7 cells prior to and following exposure to activated lymphocytes from breast cancer patients and healthy controls. Data are presented as the mean \pm standard error of the mean. Statistical comparisons were performed using Student's t-tests. ${ }^{* *} \mathrm{P}<0.001$ vs. before activation. IFN- $\gamma$ interferon $\gamma$; IL-12, interleukin 12; DC, dendritic cell; Foxp3, forkhead box P3; LDH, lactate dehydrogenase.

Tregs, which are increased in the blood and tumor microenvironment of patients with breast cancer compared with healthy subjects $(27,28)$ and its level is correlated with advanced clinical stages (29). Previous studies have emphasized the role of Tregs in the suppression of antitumor immune responses, as they are considered to exhibit critical functions in the progression and modulation of immunological escape mechanisms in malignancies. These cells express FOXP3 and CTL-associated protein-4 (CTLA-4), as negative regulatory molecules of active immune cells, and are increased in breast cancer patients $(30,31)$. Increased expression of Foxp3 and subsequently Tregs are considered obstacles that may hinder the desired response of potential immune therapeutic strategies (30-32). Therefore, in the present study the level of Foxp3 protein secreted in the media of cultured $\mathrm{T}$ lymphocytes from breast cancer patients was assessed, which demonstrated a significant decrease in Foxp3 following the subjection of T cells to tumor cell-primed DCs $(\mathrm{P}<0.001)$. This was confirmed by a significant downregulation of Foxp3 gene expression in CTLs as detected by RT-qPCR. Furthermore a significant upregulation of Foxp3 gene expression ( 12-fold higher) was observed in peripheral blood of patients compared with normal healthy controls, which was consistent with the results of Hamidinia et al (33). This was also confirmed by the inverse correlation between FOXP3 gene expression and $\mathrm{CD}^{+}{ }^{+} \mathrm{Th}$ cell levels identified in the peripheral blood of the patients enrolled in the present study. These findings suggested that the immune system was suppressed in breast cancer patients, which may be due to an augmentation in the Treg population and suppression of effector Th cells.

An alternative way to assess the efficacy of the viable cancer cell-DC based vaccine was through the detection of cytotoxicity exerted by activated CTLs on MCF-7 cells through the measurement of $\mathrm{LDH}$ release. The results demonstrated

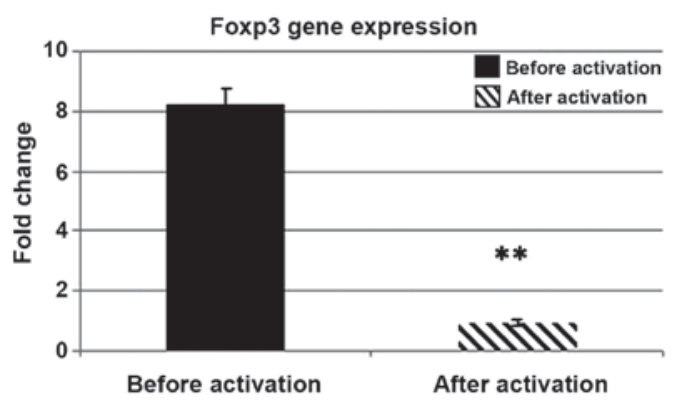

Figure 6. FOXP3 gene expression in cytotoxic T lymphocytes following activation with mature dendritic cells from breast cancer patients. Data are presented as the mean \pm standard error of the mean regarding fold change in patients in relation to control. Statistical comparisons were performed using a Student's t-test. ${ }^{* *} \mathrm{P}<0.001$ vs. before activation. FOXP3, forkhead box P3.

a significant increase in LDH level, indicting a highly active and potent immune response against these cancer cells. As described by Faloppi et al (34), LDH is typically released from necrotic cells. Therefore, the higher the degree of necrosis, which is related to tumor volume, the higher the level of $\mathrm{LDH}$. It is important to clarify that a significant positive correlation was identified between IL-12 produced by this type of viable cancer cell-based vaccine and the increased level of IFN- $\gamma$, also, IL-12 was positively correlated with increased cytotoxicity and necrosis of tumor cells via the increased level of LDH. Therefore, the current study has identified an avenue for further studying the development of novel effective immunotherapy for patients suffering from breast cancer using DCs.

In summary, the current study demonstrated that a viable cancer cells are an effective source of TAAs for pulsing DCs, which may be utilized in the immunotherapeutic treatment 
of breast cancer. The matured DCs induced expansion of TAA-specific T cells, namely CTLs and Th cells. A strong cytokine response was provoked through increased IFN- $\gamma$ and IL-12 levels. Additionally, an augmentation of the immune response was indicated by decreased Tregs and Foxp3 expression, and an elevation of CTL activity, as indicated by an increase in $\mathrm{LDH}$ release.

\section{Acknowledgements}

The present study was supported by the National Cancer Institute, Cairo University (Cairo, Egypt).

\section{References}

1. Siegel RL, Miller KD and Jemal A: Cancer statistics, 2016. CA Cancer J Clin 66: 7-30, 2016.

2. Lee J, Park S, Kim S, Kim J, Ryu J, Park HS, Kim SI and Park BW: Characteristics and survival of breast cancer patients with multiple synchronous or metachronous primary cancers. Yonsei Med J 56: 1213-1220, 2015.

3. Ibrahim AS, Khaled HM, Mikhail NN, Baraka H and Kamel H: Cancer incidence in Egypt: Results of the national population-based cancer registry program. J Cancer Epidemiol 2014: 437971, 2014.

4. Caffarel MM, Andradas C, Pérez-Gómez E, Guzmán M and Sánchez C: Cannabinoids: A new hope for breast cancer therapy? Cancer Treat Rev 38: 911-918, 2012.

5. Zhang P, Yi S, Li X, Liu R, Jiang H, Huang Z, Liu Y, Wu J and Huang Y: Preparation of triple-negative breast cancer vaccine through electrofusion with day-3 dendritic cells. PLoS One 9: e102197, 2014.

6. Berneman Z, Van de Velde A, Anguille S, Willemen Y, Huizing M, Germonpré P, Saevels K, Nijs G, Cools N, Van Driessche A, et al: Vaccination with Wilms' Tumor Antigen (WT1) mRNA-electroporated dendritic cells as an adjuvant treatment in 60 cancer patients: Report of clinical effects and increased survival in acute myeloid leukemia, metastatic breast cancer, glioblastoma and mesothelioma. Cytotherapy 18 S13-S14, 2016.

7. Bigalke I, Honnashagen K, Lundby M, Solum G, Skoge L, Inderberg EMS, Kasten J, Saboe-Larssen S, Schendel DJ and Kvalheim G: Abstract 2516: A new generation of dendritic cells to improve cancer therapy shows prolonged progression-free survival in patients with solid tumors. Cancer Res 75 (15 Suppl): S2516, 2015.

8. Song QK, Ren J, Zhou XN, Wang XL, Song GH, Di LJ, Yu J, Hobeika A, Morse MA, Yuan YH, et al: The prognostic value of peripheral $\mathrm{CD} 4{ }^{+} \mathrm{CD} 25^{+} \mathrm{T}$ lymphocytes among early stage and triple negative breast cancer patients receiving dendritic cells-cytokine induced killer cells infusion. Oncotarget 6: 41350-41359, 2015.

9. Iranpour S, Nejati V, Delirezh N, Biparva P and Shirian S: Enhanced stimulation of anti-breast cancer $\mathrm{T}$ cells responses by dendritic cells loaded with poly lactic-co-glycolic acid (PLGA) nanoparticle encapsulated tumor antigens. J Exp Clin Cancer Res 35: 168, 2016.

10. Ciccocioppo R, Ricci G, Rovati B, Pesce I, Mazzocchi S, Piancatelli D, Cagnoni A, Millimaggi D, Danova M and Corazza GR: Reduced number and function of peripheral dendritic cells in coeliac disease. Clin Exp Immunol 149: 487-496, 2007.

11. Bøyum A: Isolation of lymphocytes, granulocytes and macrophages. Scand J Immunol (Suppl 5): S9-S15, 1976.

12. Kwok S: Procedures to minimize PCR-product carry-over. PCR protocols: A Guide Met Appl: 142-145, 1990.

13. Schmittgen TD and Livak KJ: Analyzing real-time PCR data by the comparative C(T) method. Nat Protoc 3: 1101-1108, 2008.

14. Pfaffl MW: A new mathematical model for relative quantification in real-time RT-PCR. Nucleic Acids Res 29: e45, 2001.

15. Wei FQ, Sun W, Wong TS, Gao W, Wen YH, Wei JW, Wei Y and Wen WP: Eliciting cytotoxic T lymphocytes against human laryngeal cancer-derived antigens: Evaluation of dendritic cells pulsed with a heat-treated tumor lysate and other antigen-loading strategies for dendritic-cell-based vaccination. J Exp Clin Cancer Res 35: 18, 2016
16. Fields R, Shimizu K and Mulé JJ: Murine dendritic cells pulsed with whole tumor lysates mediate potent antitumor immune responses in vitro and in vivo. Proc Natl Acad Sci USA 95: 9482-9487, 1998.

17. Nesrua FO, Atuaolcl S, Gilliet M, Sun Y, Grabbe S, Dummer R, Burg G and Schadendorf D: Vaccination of melanoma patients with peptide- or tumor lysate-pulsed dendritic cells. Nat Med 4: 328-332, 1998

18. Jouanneau E, Poujol D, Gulia S, Le Mercier I, Blay J, Belin MF and Puisieux I: Dendritic cells are essential for priming but inefficient for boosting antitumour immune response in an orthotopic murine glioma model. Cancer Immunol Immunother 55: 254-267, 2006.

19. Zhang Y, Yoneyama H, Wang Y, Ishikawa S, Hashimoto S, Gao JL, Murphy P and Matsushima K: Mobilization of dendritic cell precursors into the circulation by administration of MIP-1alpha in mice. J Natl Cancer Inst 96: 201-209, 2004.

20. Hersey P, Menzies SW, Halliday GM, Nguyen T, Farrelly ML, DeSilva $\mathrm{C}$ and Lett $\mathrm{M}$ : Phase I/II study of treatment with dendritic cell vaccines in patients with disseminated melanoma. Cancer Immunol Immunother 53: 125-134, 2004.

21. Höltl L, Zelle-Rieser C, Gander H, Papesh C, Ramoner R, Bartsch G, Rogatsch H, Barsoum AL, Coggin JH Jr and Thurnher M: Immunotherapy of metastatic renal cell carcinoma with tumor lysate-pulsed autologous dendritic cells. Clin Cancer Res 8: 3369-3376, 2002.

22. Ascierto ML, Idowu MO, Zhao Y, Khalak H, Payne KK, Wang XY, Dumur CI, Bedognetti D, Tomei S, Ascierto PA, et al: Molecular signatures mostly associated with NK cells are predictive of relapse free survival in breast cancer patients. J Transl Med 11: 145, 2013.

23. Idoyaga J, Moreno J and Bonifaz L: Tumor cells prevent mouse dendritic cell maturation induced by TLR ligands. Cancer Immunol Immunother 56: 1237-1250, 2007.

24. Vieira PL, de Jong EC, Wierenga EA, Kapsenberg ML and Kaliński P: Development of Th1-inducing capacity in myeloid dendritic cells requires environmental instruction. J Immunol 164: 4507-4512, 2000.

25. Benchetrit F, Gazagne A, Adotevi O, Haicheur N, Godard B, Badoual C, Fridman WH and Tartour E: Cytotoxic T lymphocytes: Role in immunosurveillance and in immunotherapy. Bull Cancer 90: 677-685, 2003.

26. Kini Bailur J, Gueckel B and Pawelec G: Prognostic impact of high levels of circulating plasmacytoid dendritic cells in breast cancer. J Transl Med 14: 151, 2016.

27. Morse MA, Secord AA, Blackwell K, Hobeika AC, Sinnathamby G, Osada T, Hafner J, Philip M, Clay TM, Lyerly HK and Philip R: MHC class I-presented tumor antigens identified in ovarian cancer by immunoproteomic analysis are targets for T-cell responses against breast and ovarian cancer. Clin Cancer Res 17: 3408-3419, 2011.

28. Woo EY, Yeh H, Chu CS, Schlienger K, Carroll RG, Riley JL, Kaiser LR and June CH: Cutting edge: Regulatory T cells from lung cancer patients directly inhibit autologous $\mathrm{T}$ cell proliferation. J Immunol 168: 4272-4276, 2002.

29. Wang ZK, Yang B, Liu H, Hu Y, Yang JL, Wu LL, Zhou ZH and Jiao SC: Regulatory T cells increase in breast cancer and in stage IV breast cancer. Cancer Immunol Immunother 61: 911-916, 2012.

30. Jaberipour M, Habibagahi M, Hosseini A, Habibabad SR, Talei A and Ghaderi A: Increased CTLA-4 and FOXP3 transcripts in peripheral blood mononuclear cells of patients with breast cancer. Pathol Oncol Res 16: 547-551, 2010.

31. Suzuki S, Ishida T, Yoshikawa K and Ueda R: Progress in clinical use of $\mathrm{CC}$ chemokine receptor 4 antibody for regulatory $\mathrm{T}$ cell suppression. Inflam Immun Cancer: Springer: 207-227, 2015.

32. Liu F, Lang R, Zhao J, Zhang X, Pringle GA, Fan Y, Yin D, Gu F Yao Z and Fu L: $\mathrm{CD}^{+}$cytotoxic $\mathrm{T}$ cell and $\mathrm{FOXP}^{+}$regulatory $\mathrm{T}$ cell infiltration in relation to breast cancer survival and molecular subtypes. Breast Cancer Res Treat 130: 645-655, 2011.

33. Hamidinia M, Ghafourian Boroujerdnia M, Talaiezadeh A, Solgi G, Roshani R, Iranprast $S$ and Khodadadi A: Increased P-35, EBI3 transcripts and other treg markers in peripheral blood mononuclear cells of breast cancer patients with different clinical stages. Adv Pharm Bull 5: 261-267, 2015.

34. Faloppi L, Bianconi M, Memeo R, Casadei Gardini A, Giampieri R, Bittoni A, Andrikou K, Del Prete M, Cascinu S and Scartozzi M: Lactate dehydrogenase in hepatocellular carcinoma: Something old, something new. Biomed Res Int 2016: 7196280,2016 